\title{
4 Technological Choice in the Wake of Migration
}

\begin{abstract}
This chapter analyses the strategic technological decisions which Chinese rice farmers take to manage their farmland in a context of rural-urban migration. Based on ethnographic field research, it does so mainly through the example of one left-behind woman and her choice of harvesting technologies. Proposing a repertoire perspective on technological choice, the chapter sheds light on the diverse socio-technical factors behind such decision-making. It argues against a linear perspective of technological development, showing why it makes sense for farmers to simultaneously draw on a repertoire of old and new technologies, rather than simply opting for mechanization in order to compensate for the migrated labour. This also provides additional insights into the complex relationship and causalities between agricultural technology and migration.
\end{abstract}

Keywords: China, agricultural decision-making, mechanization of harvesting technology, rural-urban migration, socio-technical system, repertoires of technology

Approaching Green Water Village for the first time, I accompanied Yuemei, who was coming home after a year of migrant work in Beijing. In Green Water, she would meet her left-behind mother Mrs. Luo, her father, the construction worker Zhou Wenlu, and her two younger siblings who had also migrated, to celebrate the approaching New Year of the Rabbit. Squashed into the loading space of a three-wheeled autocycle, the main road led us directly through rice fields. The rice had already been harvested and I wondered why long stalks were sticking out of the ground in some fields, while they had been cut short in others (see Figure 5). Yuemei told me that this was related to the choice of harvesting technology, depending on whether a combine harvester or a sickle had been used.

Kaufmann, Lena, Rural-Urban Migration and Agro-Technological Change in Post-Reform China. Amsterdam, Amsterdam University Press 2021 DOI: 10.5117/9789463729734_CHO4 
Figure 5 Fields harvested with a combine harvester (left) and a sickle (right)

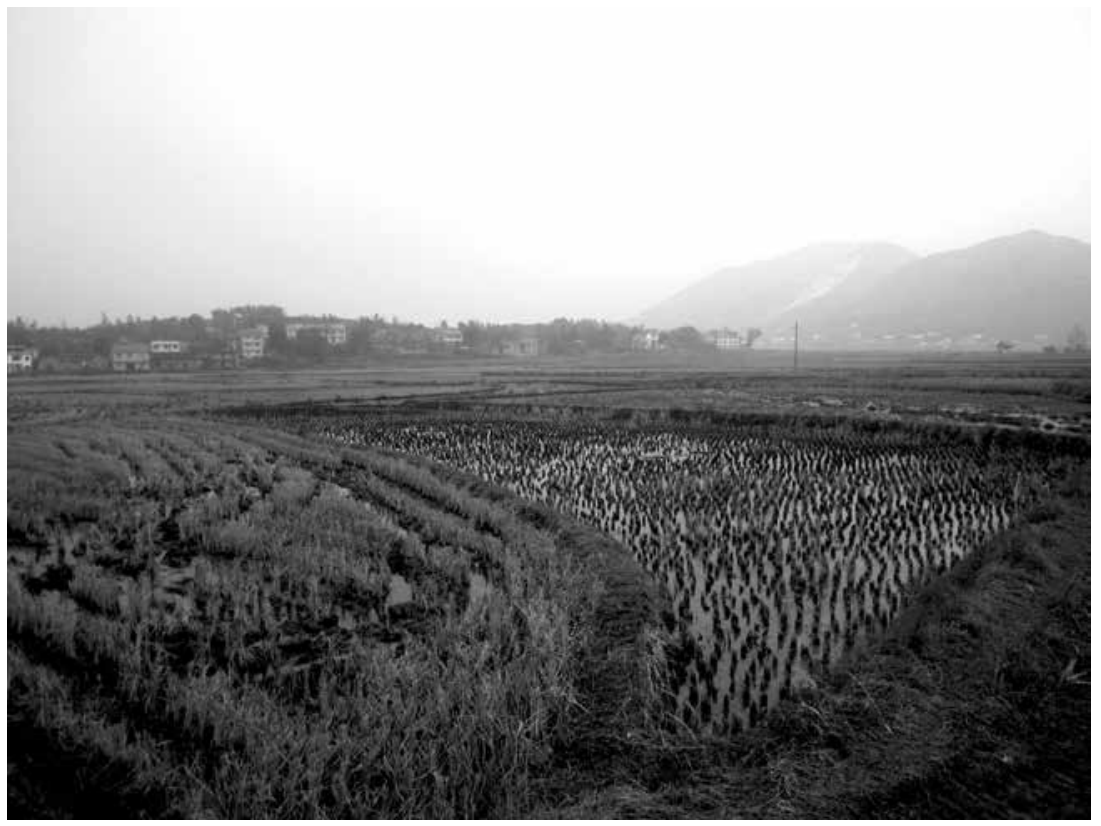

Photograph taken by the author

Upon arrival in Green Water, we were warmly welcomed by Mrs. Luo, who offered us fermented rice and other food. At nightfall, she told me to share the bed with Yuemei. There we slept - Yuemei and I head to toe - under the same cover on a thin, hard, compact yet airy mattress made of rice straw.

Mrs. Luo was a short, slim woman with a big smile. Her long black hair was tied into a loose ponytail that she had tucked under a pink knitted hat. As the village houses had no heating, in and around the house she wore brown stripey trousers, a dark blue jacket with red sleeve protectors, and colourful slippers that she had crocheted. Talking with her about harvesting, I was astonished to discover that she actually used both harvesting technologies in her fields, cutting some of her rice by hand with a sickle and some with a machine, rather than opting for just one of these two competing technologies.

Whenever I walked through the village, I paid special attention to the farming technology in use. Some tools were simply leant against houses, others were kept behind them, stored in sheds or attics. I was amazed to come across a whole potpourri of diverse technologies, ranging from stone mortars to motorized ploughs. I was struck by the way that people safeguarded them, keeping them all, even if they had stopped using them. For example, Mrs. Luo's neighbour had not disposed of her threshing tub, 
even though she used a motorized threshing machine. Mrs. Luo's brother, who lived in a nearby village, kept a manual rice mill and stones to husk rice manually. Meanwhile, Mrs. Luo's husband Zhou Wenlu took his rice to a fellow villager who owned an electric mill. I was intrigued to find out more about their choices and, as I inquired further, I found that the reasons behind choosing a particular technology were complex and, in many cases, intimately related to the phenomenon of migration. For Mrs. Luo, it was a central part of the arrangements she and her family had figured out to manage the household's fields in the face of the out-migration of her husband, her daughter Yuemei and the other two grown-up children.

Drawing on these insights, this chapter sets out from the basic assumption that there is a close relationship between technological change and social change such as the migration phenomenon. I suggest that the villagers' practices stand in contrast to the narrative conveyed by local gazetteers and statistics, which draws a rather linear picture of technological development. As Francesca Bray notes, such an understanding of technological development is also equivalent to the common-sense Western model of technological progress. It is one marked by capitalist criteria of efficiency, such as mechanization and economies of scale, which we have all internalized at school and which, for a long time, has tended to portray societies who do not implement these technologies as inferior or, in the case of China, as a failure (Bray 1994, xiv; see also Sigaut 1994, 435). However, my ethnographic research reveals a picture that, in reality, is more complex, less monocausal and linear. In this picture - a snapshot of Green Water's 'history of technology-in-use' (Edgerton 2007, xi) - farmers are not passive recipients of the new technologies promoted by the government. They are social actors who consciously choose, evaluate, and use different technologies, based on their available resources and to suit their individual circumstances.

When looking at the intersection of farming technology and migration, mechanization has generally attracted the most scholarly attention. It is now widely recognized, by scholars from various disciplines, that there is a close relation between mechanization and migration, and that the labour-saving capacities of mechanization can be a powerful way for rural households to diversify their livelihoods, by enabling some family members to take up migrant work in the cities (see, e.g., Rigg, Salamanca, and Thompson 2016).

In Green Water Village, mechanization is also often used in this way. However, it is intriguing that mechanization only partially substitutes manual technologies - despite being so vigorously promoted by the Chinese government and welcomed by many farmers for sparing them from tedious 
farmwork. I suggest that considering the issue of technological choice and migration from the perspective of the anthropology of technology may shed some light on the issue. It helps to explain why farmers use competing technologies simultaneously to protect their fields, and why they retain and store other obsolete tools. Overall, it provides some insights into the complexity of everyday life decisions and the projects that villagers pursue.

Following Barth (2002), I understand farming technologies, in their socio-technical dimension, as a medium in which paddy field knowledge is stored and transmitted as a vital part of the villagers' repertoire of knowledge for dealing with the paddy field resource. As archaeologist Helena Knutsson notes, farm tools can be used as mnemotechnic resources, improving memory 'by storing information in material objects and their treatment' (Knutsson 2014a, 278). In investigating the earliest introduction of farming to the not yet farming-focused environment of Scandinavia (about 4000-2000 B.C.E.), she claims that the new tools that were introduced can actually be seen as a 'handbook of farming practices', i.e. 'a kind of physical manual with attached narratives, which ensured the success of the [farming] enterprise' (Knutsson 2014b, 310). The idea of agricultural technology as a 'farming manual' is useful for understanding the role that particular technologies play in the specific layout and transmission of the overall system of farming knowledge. In Green Water Village and other rice farming areas, while well-known and long-used tools retain knowledge, new tools introduced into this system are mnemotechnic resources that represent new solutions for particular problems in rice farming.

Technologies do not stand alone. They are are 'imbued with meaning, acquired, transmitted, and performed in a social context' (Smerdel 2014, 286). In order to be effective as knowledge stores, they require a practitioner to use them with the help of their skilled body. Anderson and colleagues speak of 'muscle memory', referring to agricultural skills that have gradually become incorporated in farmers' bodies (Anderson et al. 2014, 5). As the aspect of the skilled body has already been discussed in Chapter 2, I will not refer to it explicitly below. Nevertheless, I conceive the body as well as the wider community of practice in which knowledge about tools is developed, practiced, and transmitted as integral elements of the technologies described. In view of this, it is useful to distinguish between technologies and techniques. Drawing on Francesca Bray, I understand technology broadly as 'social-material networks or systems, including sets of techniques and equipment, but also trained personnel, raw materials, ideas and institutions' (Bray 2008, 320). In this chapter, I mainly focus on farm tools and machines as two specific types of technology, and less on 
'techniques', although I do include some in my descriptions when they compete with or complement certain technologies. 'Techniques' denote 'the skilled practices that go into the material production of knowledge as well as the production of artefacts' (ibid.). In practice, all technologies require certain techniques of handling, and all techniques have a level of interaction that includes components such as the body or a tool.

What is more, technologies and techniques are never merely technical, but always also socio-cultural productions (Lemonnier 1993b). It is therefore highly relevant to look at technological choices in order to better understand Chinese households' strategies for coping with their predicament. According to Pierre Lemonnier, the term 'technological choices' highlights 'the sorting of possibilities on which the development of a technical system is de facto based' (Lemonnier 2012, 301). It refers to the process of selection as well as to its results. Which farming technologies are used in practice depends on various factors. While Lemonnier adopts a long-term perspective that spans several millennia, stating that technological choice mostly happens unconsciously and unintentionally (ibid.), I focus on farmers' more immediate situations and argue that their choice is clearly strategic. Moreover, it is not necessarily exclusive. Together, the repertoire of technologies can provide solutions to different socio-technical problems that have occurred before and may potentially reoccur again, in the form of, for instance, a shortage of fuel, electricity or cash, or a wave of return migration due to an economic crisis.

\section{Tilling with power ploughs and oxen}

One brief example of strategic choice relates to tilling technology. The main tool used in Green Water Village for deeper tillage is the plough, either pulled by oxen or operated with motors. Moreover, there is a whole range of other tillage tools, which mostly serve for surface operations. Most households around Green Water use a power plough. While in 2011 they did not always own one, they could rent one from other villagers at the cost of 90 to 100 Yuan (about 13 to 14 USD) per $m u$. Farmers from nearby Paishan County reported paying only half that price. In any case, only one or two hours were needed to plough one $m u$ with this machine (see Figure 6).

In contrast, as several Green Water villagers explained to me in 2011 and 2017, an ox would take a whole day to plough the same amount of land. Moreover, an ox needs to be tended and grazed, and the farmer needs to pay attention to it, making sure that the animal does not eat or 
Figure 6 Field preparation with a power plough

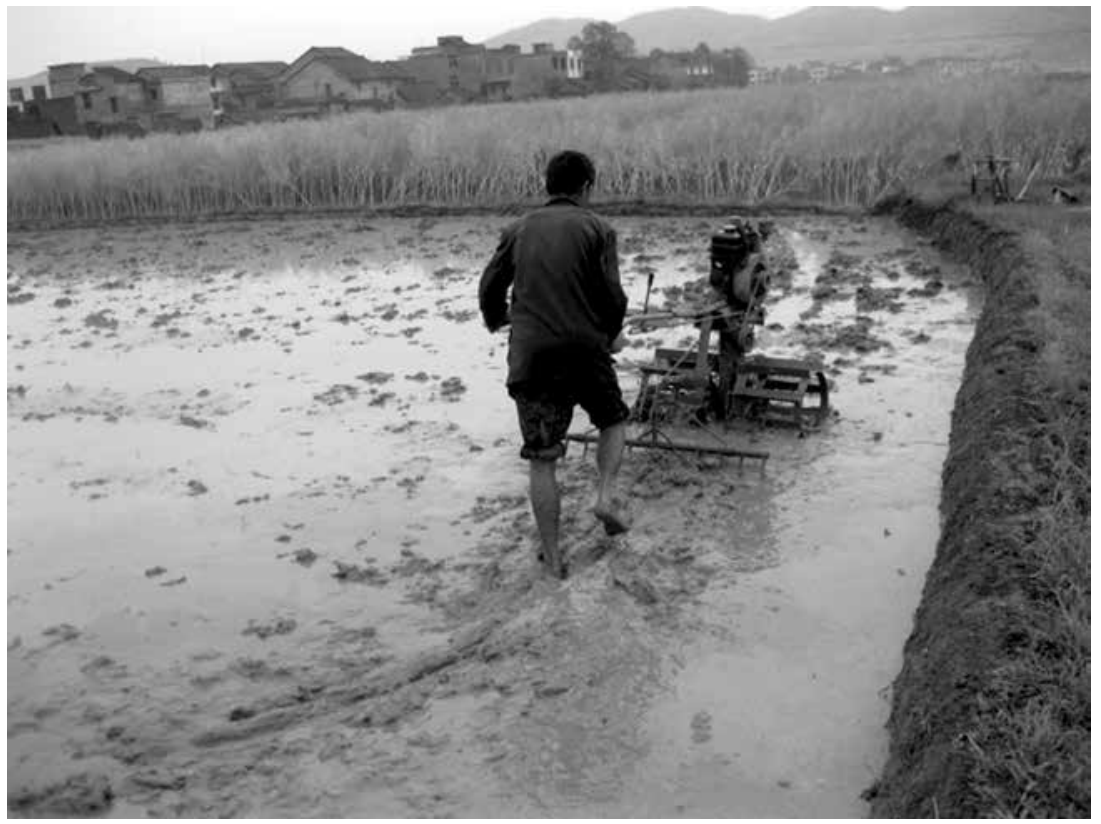

Photograph taken by Zhou Yuemei

trample on other farmers' crops (see also Perdue 1987, 133). Nevertheless, it remains useful. First, some fields are so 'deep and soft' that a machine would get stuck in them, so they can only be ploughed with the help of cattle. Second, it is cheaper to use cattle than rent a machine. Besides, oxen serve as a form of insurance, since they can be sold for cash in times of need. Moreover, their dung can be used as manure, as stated in the following proverb: 'The dung of an ox fertilizes three fields of seedlings' (yi tiao niu de fen, san miao tian de fen) (XT 1988, 230). Oxen manure is cheaper, and better quality, than chemical fertilizer. These are some of the reasons why some households continued to raise and use oxen, either alone or in combination with tilling machinery. Moreover, they also continued to use hoes, an indispensable and multifunctional tool. While it would be possible (although labour-intensive) to use only a hoe for field preparation, in the 2010s the Green Water villagers employed it in spaces that were inaccessible to oxen and machines, such as the corners of a field. In making their choices, they thus considered a whole range of factors. Among these, financial and time considerations were especially important when it came to migration, as in the case of Yongcai's household, who stopped raising oxen when the three sons migrated. 


\section{Harvesting with sickles and combine harvesters}

A second example of strategic choice is even more complex and concerns harvesting technology. Harvesting technology is particularly apt for looking at strategic choices, because the harvest represents one of the two peak seasons in rice farming (see Chapters 2 and 5 for planting). In order not to lose any of the harvest, the activity has to be carried out quickly, i.e. within a time frame of only ten days. In this context, the combine harvester is especially appealing for migrant households who lack labour. However, the sickle also retains some advantages and - as the case of Mrs. Luo shows - it is not a simple choice of either/or. Rather, the two technologies present elements in a repertoire from which to choose, according to varying household circumstances.

Sickles are the conventional harvesting implement in Green Water Village. Today's sickles are industrial products (see Figure 7). Since about 2006, sickles with wooden or plastic handles have been produced, which may be purchased for less than five Yuan (about 0.7 USD) at the local market. According to Grandpa Luo, a part-time carpenter, these last for about five years, two years longer than hand-crafted sickles (personal interview, 24 January 2011). Harvesting with a sickle is performed by grabbing a bushel of the ripe rice plant with the left hand, while the right hand cuts the bushel several centimetres above the ground, making a movement close to the ground swiping from right to left, towards the body. Thus, the upper part of the body is bent towards the field, and the knees are slightly bent (see also Bray 1984, 335).

For an in-depth understanding of the use and choice of the sickle, it is useful to draw on the comparative insights of François Sigaut. According to Sigaut, using a sickle has been the dominant harvesting technique in Europe, Asia and North Africa for many centuries. In his analysis, Sigaut highlighted important connections between the tool and the harvested product. These also apply to Green Water Village and contribute towards rendering the choice of harvesting technology so complex. In his descriptive classification, or 'technical lineage' (lignée technique) of harvesting tools, the sickle-technique is the eighth of nine techniques Sigaut outlined. Each technique involves a certain 'way of action' (mode d'action) (pulling out, picking up, beating, stripping off, breaking off, cutting through pressure, cutting through friction, cutting through friction with a launched tool) to obtain a certain 'product' (produit) (whole plants, grains and spikelets, spikes and panicles, a handful of stalks, an ensemble of stalks) (see Sigaut 1991, 33, 37). 
Figure 7 A hand-made sickle (above) and an industrially-produced sickle (below)

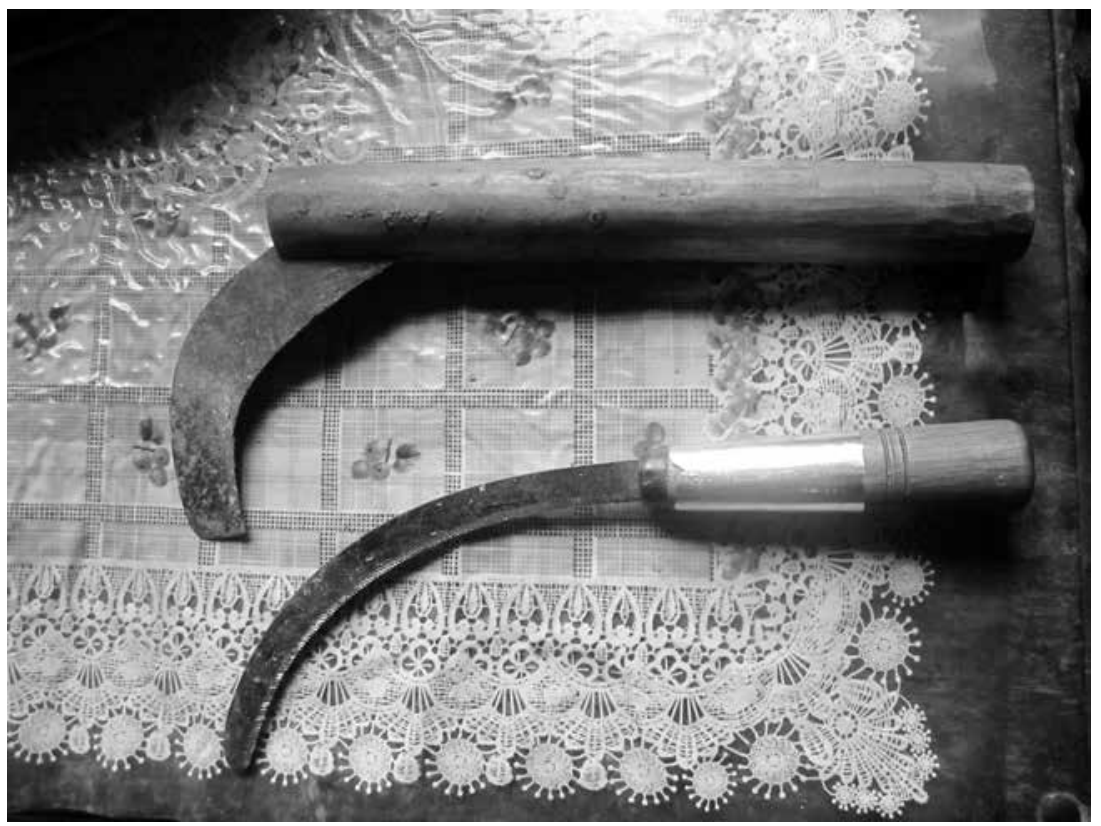

Photograph taken by the author

According to this classificatory scheme, the sickle collects a handful of stalks' (une poignée de tiges) held in one hand by 'cutting' (couper) them with the other hand 'through friction' (parfriction). This technique is particular with regard to the stalks, because it implies that the cut ears of the grain are not cut off, but they rest on the stalks. ${ }^{1}$ On the one hand, this is safer for the cutter, as it grants a security distance between tool and body. On the other hand, keeping part of the stalk on the harvested grain enables collecting, transporting, and processing the harvested grain in characteristic sheafs (Sigaut 1991, 33, 37). The sickle is therefore seen as the technological solution to harvesting the straw together with the grain, implying that the straw is valuable enough to deserve the extra effort in threshing and transport (Anderson and Sigaut 2014, 90).

Moreover, there is a linkage between tool and farm animals. In this regard, Sigaut suggested some interesting connections between the usage of a sickle and the usage of animal power. He asserted that, unlike a harvesting knife or manual harvesting, the sickle can cut considerable amounts of grain at

1 For the strategic advantages of using a finger knife to cut just the grain, see Miles (1979) and Bray (1984, 330). 
once. This bigger amount implies higher requirements for the labour needed for transportation and threshing, leading him to conclude that it would seem to only be economical to use sickles in combination with (draught) animal power. At the same time, it valorizes the straw produced, making it usable as fodder and litter for the animal (Sigaut 1991, 41). The latter certainly used to be the case in Green Water Village.

Sickles also have implications with regard to gender and the social organization of sickle-harvesting knowledge. Sigaut claimed that, while the more nimble-fingered harvesting techniques such as finger knives exclusively required women's labour, sickles is done by various groups. Harvesting with a sickle is typically a woman's task in non-Mediterranean Europe and India, but a man's task in the semi-arid areas of Morocco, Spain, central Asia and north China (ibid., 41-42). In southern China's Green Water Village, harvesting with a sickle is performed across age and gender boundaries. Yuemei recalls harvesting from her school years in the 199os, when children were sent to the harvested field to glean, i.e. collect left-over rice panicles and kernels by hand. ${ }^{2}$ This was an aspect of the 'part-work and part-study system' (qin gong jian xue), comprising both educational activity and contributing to society. Generally, however, she added that men, women, and children (including herself) all had to help harvesting with a sickle, and nobody was spared from the hectic job of cutting the grain (personal and text conversations, 23 January 2011 and 24 November 2016). In view of enskilment, this may be seen as an important step in ensuring that children acquire the skills for rice farming. The introduction of the combine harvester has certainly transformed this practice.

Combine harvesters have only recently been introduced to Anren County through a county government initiative. According to the Anren County Gazetteer, rice was harvested mechanically in Anren for the first time in October 1998. At that time, the County Department of Agriculture had invested more than 100,000 Yuan (about 14,130 USD) to purchase a combine harvester from Zhejiang Province. More than 3000 people are reported to have watched the spectacle of a demonstration by this exciting new vehicle. In 2000-2001 the department brought in six more machines, setting up teams to provide machine-harvesting services for local farmers for $5_{0}$ Yuan (about 7 USD) per $m u$. Next came 30 new combine harvesters in 2003, processing 2490 hectares, which corresponds to about 10 percent of the total arable area (ACGCC 2011, 284, 300-302). In addition, several privately-owned combine harvesters are kept in the area. Hunan has a relatively high number of 
Figure 8 The only combine harvester in Green Water

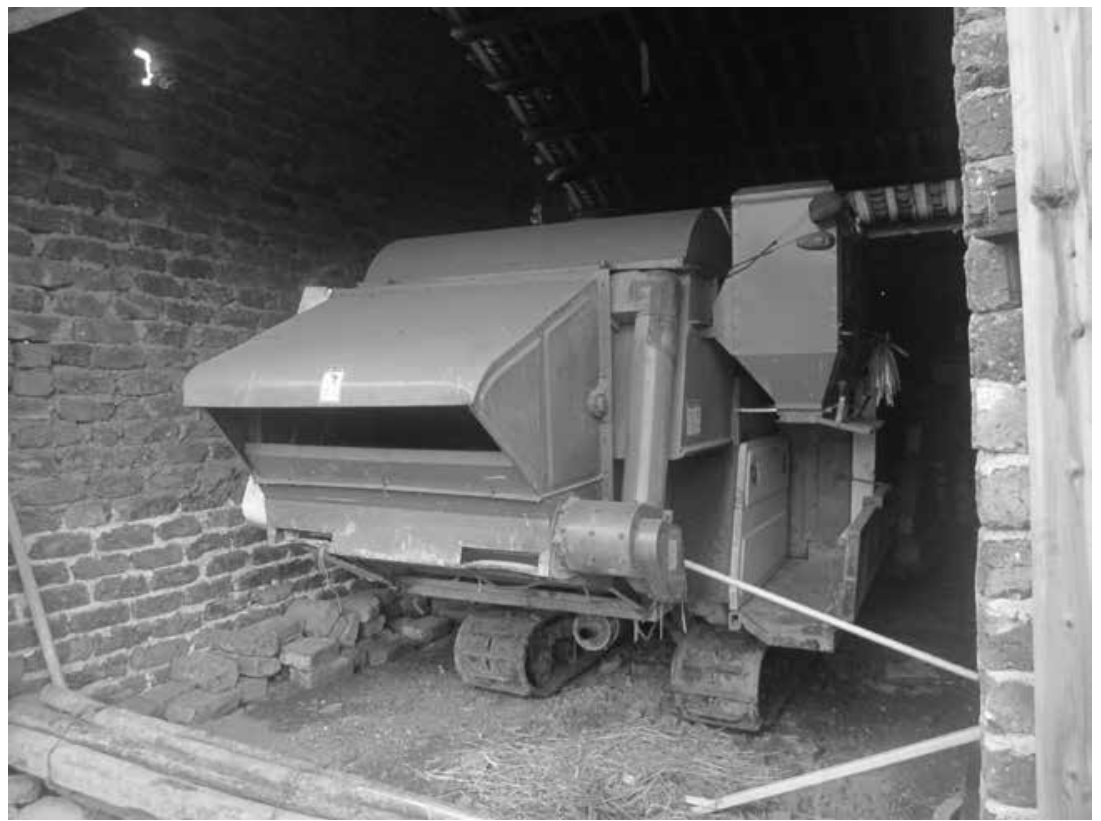

Photograph taken by the author

combine harvesters - a machine which is not common in every Chinese rice growing area - compared to other Chinese provinces. With around 130,000 combine harvesters in 2018, the province ranks sixth nationally (NBSC 2019). In fact, between 2000 and 2018 alone, there has been a more than forty-fold increase in combine harvesters in Hunan (HPBS 2019, sec. 12-8).

The farmers from Green Water confirmed that combine harvesters were a very recent innovation. Only the richest farmers could afford them - there was just one machine in Green Water Village, which Hugen's family had purchased in 2007 (see Figure 8). In 2011, Hugen was a stout and confident villager in his early thirties, practising seasonal migration to raise his two children, one each from his current and former wives. He also owned the largest house, and his household was said to be the richest in Green Water. Hugen stated that the combine harvester had cost 50,000 Yuan (about 7060 USD) and that his family had saved up for eight years to buy it (personal interview, 1 February 2011).

Ever since Hugen's family bought the combine harvester, Green Water villagers had been using it for cutting and threshing. They paid Hugen up to 100 Yuan (about 14 USD) per $m u$, a considerable cost that not everybody was willing or able to afford. Hiring manual harvesting services to replace the 
missing labour would be even more expensive (see Chen 2016), which is why some farmers continued to rely on the household labour they had available.

Despite its high cost, the combine harvester wrought considerable time and labour savings. Hugen explained that it took about ten minutes for him to harvest one $m u$. Only one person was needed to run the machine, with a second one walking behind it to put the rice into bags. In contrast, four people would take about one day to harvest one $m u$ manually. This is an important factor when it comes to making technological choices when faced with off-farm migration. Renting the services of a combine harvester means that migrant workers do not need to return for the busy harvesting season. Besides, it has enabled villagers such as left-behind women to pay somebody else for the task of harvesting, rather than performing it themselves or engaging in labour exchange (personal and text conversations in 2011 and 2016).

With regard to the division of labour and knowledge, it is notable that combine harvesters in Hunan are operated exclusively by men, sparing women, children, and migrants from much of the harvesting work. Mrs. Luo's husband Zhou Wenlu sees this in relation to the complex and uneven physical features of the terrain, which render it difficult to operate the machine. In contrast, he states that it is easier to drive a combine harvester in the flat terrain of northern China, which is why women there can also drive a combine harvester (text conversation, 29 April 2017). Here it is worth noting that certain new skills are needed to drive a combine harvester, and that the new technology and the skills to operate it are attributed only to men, which points towards the transformation of the knowledge system, including the issue of deskilling discussed in Chapter 2.

\section{Choosing harvesting technologies}

Regarding the choice between a sickle and a combine harvester, both technologies ensure the cultivation and, hence, the protection of the rice field. At the same time, each of them has certain advantages and disadvantages that farmers weigh against each other. My aim here is not to provide an exhaustive list of factors around decision making, but rather to suggest that the choice is indeed complex and goes beyond simple economic reasoning.

Labour and costs are the two central factors Green Water villagers take into account when choosing between a sickle or a combine harvester. They are also interconnected when it comes to opting for mechanization in the context of migration. On the one hand, migrant remittances - as well as 
migrants' skills to earn them - enable those remaining in the village to afford harvesting services, as in the case of left-behind woman Mrs. Luo, or to invest in purchasing machines, like combine harvester owner Hugen. On the other hand, the need to replace migrated labour through labour-saving technology is obvious. This is related to the double effect of migration on agriculture through missing labour and increased cash income through remittances, which has been widely documented in studies examining the impact of migration on agricultural production (see, e.g., Davis, Carletto, and Winters 2010).

Reality is more complex, however, and farmers not only consider the financial and human capital available for making technological choices. When it comes to harvesting, the choice of method is generally related to the following factors: the desired part of the plant, including the possible use of the stems; plant morphology; field density; and soil type (Anderson and Sigaut 2014, 92). Moreover, different techniques and technologies affect each other, because farming is a system (Sigaut 1991). Whittaker compares this mutual influence to interdependent organisms in a given system. From this perspective, technologies 'occupy a particular functional niche within their social and technical environment, interacting and sometimes competing with other technologies' (Whittaker 2014a, 355). His analogy helps to better understand the competitions and dynamics between different technologies. In Green Water Village in 2011 both sickles and the combine harvester coexisted. This is, because a 'technology [here the sickle] survives as long as it maintains a competitive edge - technical, economic, or even social - over technologies with similar functions [here the combine harvester]' (ibid.).

The combine harvester's main competitive edge, in view of the missing emigrated labour, is certainly its labour-saving capacity. In contrast, sickles are not only a low-cost implement, but they also cut the plants closely to the ground and therefore have the competitive advantage of producing rice straw. This is in contrast to the long, standing rice straw that the combine harvester leaves behind on the field, as described in the introduction of this chapter. That straw is lost and cannot be used for other purposes (see Chapter 2). Although increased cash incomes through migration have rendered farmers more independent from the product of rice straw, they still need to decide and weigh up if this independence is affordable or makes sense.

Within the sphere of farming, one of rice straw's main purposes is to produce fodder for the oxen. Because oxen are first and foremost kept as ploughing animals, a change in harvesting technology directly affects the choice of ploughing technology. This is an inverse instance that perfectly confirms the close connection between the sickle harvesting technique and 
the use of draught animals observed by Sigaut (1991, 41). Moreover, regarding the connection between instructing animals and instructing children mentioned in Chapter 2, the influence of harvesting technology on ploughing technology will eventually have consequences for the transmission of rice farming skills in many other realms besides harvesting.

In addition, the choice of a different harvesting technology also means that, as ever more grain is harvested, farmers will need to depend on new means of carrying, threshing and processing this higher volume (ibid.). There is a clear connection to the harvesting method applied prior to threshing and, more generally, to the whole chaîne opératoire or 'operational sequence' of the entire agricultural process (Leroi-Gourhan 1964; Anderson 2014). Aware of how rice farming machines affect the use of other machines, Oshiro $(1985,328)$ has termed this 'technical linkage', and singled out this linkage as one decision-making factor in purchasing harvesting and other farm machinery in Japan.

The combine harvester - a machine that combines the tasks of harvesting and threshing - also illustrates that the shift in threshing technology is affected by a shift in harvesting technology. Nevertheless, the combine harvester is singular, because it only produces the grain. Here it becomes evident that, like the choice of harvesting technology, the method chosen for threshing is strongly connected to the product desired, e.g. grain, straw in whole stems, broken straw; for human or animal consumption; or as a building material. Moreover, as Whittaker shows, the choice is linked to many other interrelated factors, e.g. social, environmental, crop-specific, and technological (see Whittaker 2014b).

Besides these more complex considerations, there are a whole range of further practical factors that come into play when choosing between a sickle and a combine harvester. First, as Grandpa Zhou stated, the amount of rice planted was a factor in the decision: if farmers cultivated little rice (an option favoured by many left-behind household members), i.e. less than one $m u$, they generally preferred to use a sickle for harvesting (personal interview, 28 January 2011). One-to-three $m u$ of rice fields, explained Zhou Wenlu however, was a good size for using a combine harvester (text conversation, 29 April 2017). A smaller cultivated area could be managed with manual techniques in the given time frame, even with few people. At the same time, the human harvesters did not have to bear the financial burden of machine harvesting.

Second, because not every plot was suitable for machine harvesting, the size of the field played a role. In Hugen's words, if a field was too small, the combine harvester 'cannot enter' it. This echoes the findings of other 
scholars on the relation between farm size and mechanization. For example, Tian et al. $(2015,1249)$ state that, in nearby Poyang, Jiangxi Province, a combine harvester is used on larger and flatter plots, which then also has an influence on crop choice (rice or cotton). An awareness of this relationship between mechanization and farm size has led policy makers in China and elsewhere to conclude that bigger farms are a necessary precondition for modernizing farming (see Rigg, Salamanca, and Thompson 2016, 119). However, despite Green Water villagers' use of machines on bigger plots, in the overall picture of the resilience of smallholder or family farms, and in the ongoing debate about whether mechanization actually fosters bigger farm sizes or supports small farms, my findings point towards the latter. Green Water villagers use mechanization to ensure cultivation and, hence, to protect fields for the family; but generally empirical findings on the issue remain inconclusive (ibid., 125-126).

Third, the shape of a field and the characteristics of the soil are important. For instance, Mrs. Luo used a sickle in some parts of her field, and a combine harvester in other parts of the same field. This was because the machine would get stuck in the mud in certain places. This was also confirmed by Grandpa Zhou and by the combine harvester's owner, Hugen, who explained that he would not drive his combine harvester into a field if there was too much water in it and the soil was too muddy (personal interviews in January-February 2011). ${ }^{3}$

Overall, the complexity of factors that come into play outlined here - which provide merely a glimpse into the issue of technology choice contribute to explaining why scholars have not yet been able to clearly determine the relationship between migration and the adoption of agricultural mechanization, despite numerous efforts to do so (see Rigg, Salamanca, and Thompson 2016, 125). Other factors not mentioned here may involve further practical issues, such as the way a crop is sown (i.e. broadcast or transplanted) and the way it ripens (evenly or at different stages) (Bray 1984, $322,335)$, the availability of subsidies for machinery and extension services, as well as socio-cultural factors. For example, mechanization frees up fragile left-behind elderly people to offer their labour in exchange, or gives other households with several members the possibility of offering their labour in return for cash or other favours. Other examples are influences based on gender and age (see Song 1998; Yuan and Niehof 2011), political factors, or the use of certain technologies as markers of status or identity (Lemonnier 1993a, 18-19). Furthermore, in reviewing the factors around purchasing combine 
harvesters when they first reached Japan in the 1970s, Oshiro (1985) finds that critical 'time windows' for accomplishing certain tasks, time saved which can be used for other income-generating activities, loans, reduction of heavy work, desire for ownership, social values (the feeling of being a modern farmer), village dynamics (having an equal status with others), and technical linkages all played a role.

The association of certain techniques and technologies with 'backwards' or 'modern' farming practices also arose in Green Water village. For example, in comparing stone mills and mechanized mills, Grandpa Zhou held the opinion that the stone mill was an 'underdeveloped machine' (bu fada dejiqi) and he preferred to mill his rice mechanically rather than manually (personal interview, 28 January 2011). Similarly, the villagers perceived combine harvesters and other machines as 'modern'. This deprecation shows clear parallels to the perception of traditional toilet and fertilizing techniques as backwards, as mentioned by Santos $(2011,497)$, and to the pervasive narrative of linear technological development underlying the local gazetteers. This hints at the discursive level of technology adoption, which is not necessarily congruent with actual practices. In fact, it seems that in practice Green Water farmers' perceptions of 'modern' and 'backward' farm implements only had a minor impact on their choices. Other factors around mechanization weighed heavier, said Luo Baowen - for example, that a machine would get through the work 'very quickly' and 'doesn't make [you] too tired', or that it 'sets free the labour force' (jiefang laodong li) (personal interview, 22 January 2011). Nevertheless, the hint at modernity shows how pervasive the narrative of farmers and backwardness in contrast to science and modernity is, persistent to a degree that not just state agents, but even farmers themselves refer to it (Schmalzer 2016, 108-109).

\section{Technological choice from a repertoire perspective}

Chinese rice farmers now have at their disposal several generations of farm implements. Each of these technologies provides solutions for particular problems in dealing with the paddy field resource under varying circumstances. In adopting certain agricultural technologies, farmers weigh up multifaceted practical factors - not just considerations of the available labour and financial capital. Technological choices involve numerous factors, ranging from the technical-ecological to the socio-cultural (Lemonnier, 1993b). Moreover, because farming is a socio-technical system, the outcomes 
of particular choices often affect other spheres of the system, which renders the choice even more complex.

Here, however, I would like to shift the focus: away from these distinguishing decision-making factors, towards highlighting the repertoire character of the knowledge and skills inscribed in these technologies that underlie technological choice; and away from discourse towards practice. In fact, as Lemonnier notes, 'it seems that societies choose between a number of possible technical solutions', some of which may at first sight appear illogical in terms of their material achievements, but nevertheless follow their own socio-cultural logics (Lemonnier 1993a, 16). Such a repertoire perspective contrasts with the standard narrative of linear development, in which 'new' replaces 'old', as presented in official discourse and partly also in farmers' discourse on 'backwards' and 'modern'.

In this regard, a look at actual agricultural practices reveals that Green Water villagers in fact make use of many 'non-synchronous's technologies simultaneously, which also occurs in other farming systems around the world (see van Gijn, Whittaker, and Anderson 2014). In Green Water Village, it is most obviously exemplified by the simultaneous use of the oxen and 'power plough', the sickle and the combine harvester, as well as by the coinciding practices of transplanting and direct seeding. From a repertoire perspective it becomes clear that farmers are taking up technologies strategically in a way that best fits their current circumstances and constraints. This also partly explains why some seemingly old technologies persist, despite strong government and economic incentives to replace them with newer ones.

Finally, a repertoire perspective also sheds light on causalities. With reference to the long-standing debate about the causal relationship between agro-technological change and population size (Malthus 1798; Boserup 1965), the case of Green Water Village contributes to highlighting the complexity of factors revealed by post-Boserupian research, including ecological, political-economic, and social factors (see Stone 2001). Regarding the more immediate question of whether new technologies cause migration through freeing up labour, or whether migration causes the adoption of new technologies because of the need to replace labour, and through the availability of remittances to invest in technology, my data suggest that the situation is, in fact, multicausal. In the first instance, the introduction of labour-saving technologies in combination with the introduction of the household system in the 1980 s certainly set free millions of farmers. In the

4 The concept of non-synchronicity goes back to the German Marxist philosopher Ernst Bloch (1885-1977). For more about its origin and more recent adoptions, see Flitsch $(2008,270)$. 
twenty-first century, these technologies have become an established part of farmers' household strategies that can be used strategically to enable part of the household to pursue migrant work in the city - or abandoned again according to complex socio-technical logics.

\section{References}

ACGCC, 安仁县志编纂委员会 Anren Xianzhi Bianji Weiyuanhui (Anren County Gazetteer Compilation Committee). 2011. 安仁县志 Anren Xianzhi, 1989-2003 (Anren County Gazetteer, 1989-2003). Changsha: Hunan Renmin Publishing.

Anderson, Patricia C. 2014. 'Trampling the Crops with Animals'. In Exploring and Explaining Diversity in Agricultural Technology, edited by Annelou van Gijn, John C. Whittaker, and Patricia C. Anderson, 138-140. Oxford: Oxbow.

Anderson, Patricia C., Annelou van Gijn, John C. Whittaker, and François Sigaut. 2014. 'The Dimension of Tools, Skills and Processes: Exploring Diversity'. In Exploring and Explaining Diversity in Agricultural Technology, edited by Annelou van Gijn, John C. Whittaker, and Patricia C. Anderson, 3-15. Oxford: Oxbow.

Anderson, Patricia C, and François Sigaut. 2014. 'Introduction: Reasons for Variability in Harvesting Techniques and Tools'. In Exploring and Explaining Diversity in Agricultural Technology, edited by Annelou van Gijn, John C. Whittaker, and Patricia C. Anderson, 85-92. Oxford: Oxbow.

Barth, Fredrik. 2002. 'An Anthropology of Knowledge'. Current Anthropology 43 (1): 1-18.

Boserup, Ester. 1965. The Conditions of Agricultural Growth: The Economics of Agrarian Change under Population Pressure. London: Allen \& Unwin.

Bray, Francesca. 1984. Agriculture. In Science and Civilisation in China, Vol. 6, Part 2, edited by Joseph Needham. Cambridge: Cambridge University Press.

-. 1994. The Rice Economies: Technology and Development in Asian Societies. Reprint. Berkeley: University of California Press.

-. 2008. 'Science, Technique, Technology: Passages between Matter and Knowledge in Imperial Chinese Agriculture'. The British Journal for the History of Science 41 (3): 319-344.

Chen, Chunhong 陈春红. 2016. 晾晒难收割难 水稻收获两痛点如何破解 Liangshai nan shouge nan shuidao shouhuo liang tongdian ruhe pojie (Drying Is Difficult, Harvesting Is Difficult: How to Break the Two Sorrows of Harvesting Paddy Rice)'. 中国农机化导报 China Agricultural Mechanization Herald. 30 August 2016. Accessed 9 September 2016. http://www.camn.agri.gov.cn/Ht ml/2016_08_30/2_1842_2016_08_30_30001.html. 
Davis, Benjamin, Gero Carletto, and Paul C. Winters. 2010. 'Migration, Transfers and Economic Decision Making among Agricultural Households: An Introduction'. The Journal of Development Studies 46 (1): 1-13.

Edgerton, David. 2007. The Shock of the Old: Technology and Global History since 1900. Oxford: Oxford University Press.

Flitsch, Mareile. 2008. 'Knowledge, Embodiment, Skill and Risk: Anthropological Perspectives on Women's Everyday Technologies in Rural North China'. East Asian Science, Technology and Society 2 (2): 265-288.

van Gijn, Annelou, John Whittaker, and Patricia C. Anderson, eds. 2014. Exploring and Explaining Diversity in Agricultural Technology. Oxford: Oxbow.

HPBS, Hunan Provincial Bureau of Statistics. 2019. Hunan Statistical Yearbook 2019. Beijing: China Statistics Press.

Knutsson, Helena. 2014a. 'Blades as Messengers of Agriculture: A Case Study from Scandinavia'. In Exploring and Explaining Diversity in Agricultural Technology, edited by Annelou van Gijn, John C. Whittaker, and Patricia C. Anderson, 278-285. Oxford: Oxbow.

-.2014b. 'The Complex Art of Changing Lifestyles on the Verge of the Neolithic'. In Exploring and Explaining Diversity in Agricultural Technology, edited by Annelou van Gijn, John C. Whittaker, and Patricia C. Anderson, 295-310. Oxford: Oxbow.

Lemonnier, Pierre. 1993a. 'Introduction'. In Technological Choices: Transformation in Material Cultures Since the Neolithic, edited by Pierre Lemonnier, 1-34. Oxford: Oxford University Press.

—. , ed. 1993b. Technological Choices: Transformation in Material Cultures Since the Neolithic. London: Routledge.

- 2012. 'Technology'. In The Oxford Handbook of Linguistic Fieldwork, edited by Nick Thieberger, 298-316. Oxford: Oxford University Press.

Leroi-Gourhan, André. 1964. Le geste et la parole I: Techniques et langage. Paris: Albin Michel.

Malthus, Thomas. 1798. An Essay on the Principle of Population. Reprinted in 1986. Harmondsworth: Penguin Classics.

Miles, Douglas. 1979. 'The Finger Knife and Ockham's Razor: A Problem in Asian Culture History and Economic Anthropology'. American Ethnologist 6 (2): $223-243$.

NBSC, National Bureau of Statistics of China. 2019. 'National Data: Annual by Province'. Accessed 6 January 2020. http://data.stats.gov.cn/english/easyquery. htm?cn=E0103.

Oshiro, Kenji K. 1985. 'Mechanization of Rice Production in Japan'. Economic Geography 61 (4): 323-331.

Perdue, Peter C. 1987. Exhausting the Earth: State and Peasant in Hunan, 1500-1850. Cambridge, MA: Harvard University Press. 
Rigg, Jonathan, Albert Salamanca, and Eric C. Thompson. 2016. 'The Puzzle of East and Southeast Asia's Persistent Smallholder'. Journal of Rural Studies 43: 118-133.

Santos, Gonçalo. 2011. 'Rethinking the Green Revolution in South China: Technological Materialities and Human-Environment Relations'. East Asian Science, Technology and Society 5 (4): 479-504.

Schmalzer, Sigrid. 2016. Red Revolution, Green Revolution: Scientific Farming in Socialist China. Chicago: University of Chicago Press.

Sigaut, François. 1991. 'Les techniques de récolte des grains: Identification, localisation, problèmes d'interprétation'. In Rites et rythmes agraires: Séminaire de recherche, edited by Marie-Claire Cauvin, 31-43. Lyon: GDR-Maison de l'Orient.

-. 1994. 'Technology'. In Companion Encyclopedia of Anthropology, edited by Tim Ingold, 420-459. London: Routledge.

Smerdel, Inja. 2014. 'Concluding Remarks'. In Exploring and Explaining Diversity in Agricultural Technology, edited by Annelou van Gijn, John C. Whittaker, and Patricia C. Anderson, 286. Oxford: Oxbow.

Song, Yiching. 1998. "New" Seed in "Old” China: Impact of CIMMYT Collaborative Programme on Maize Breeding in South-Western China'. PhD diss., Wageningen University.

Stone, Glenn Davis. 2001. 'Theory of the Square Chicken: Advances in Agricultural Intensification Theory'. Asia Pacific Viewpoint 42 (2-3): 163-180.

Tian, Qing, Daniel G. Brown, Lin Zheng, Shuhua Qi, Ying Liu, and Luguang Jiang. 2015. 'The Role of Cross-Scale Social and Environmental Contexts in HouseholdLevel Land-Use Decisions, Poyang Lake Region, China'. Annals of the Association of American Geographers 105 (6): 1240-1259.

Whittaker, John C. 2014a. 'Some Principles of Technological Decline: The Case of the Tribulum'. In Exploring and Explaining Diversity in Agricultural Technology, edited by Annelou van Gijn, John C. Whittaker, and Patricia C. Anderson, 355-356. Oxford: Oxbow.

-. 2014b. 'Threshing Processes and Tools - Exploring Diversity in the Past: An Introduction'. In Exploring and Explaining Diversity in Agricultural Technology, edited by Annelou van Gijn, John C. Whittaker, and Patricia C. Anderson, 133-135. Oxford: Oxbow.

XT, 湘潭市民间文学集成编委会 Xiangtan Shi Minjian Wenxue Jicheng Bianweihui (Editorial Board of the Comprehensive Collection of the Folk Literature of Xiangtan City), ed. 1988. 中国谚语集成湖南卷: 湘潭市分卷 Zhongguo yanyu jicheng Hunan juan: Xiangtan shifen juan (Hunan Volume of the Comprehensive Collection of Chinese Proverbs: Section Volume of Xiangtan City). Xiangtan: N.p. Yuan, Juanwen, and Anke Niehof. 2011. 'Agricultural Technology Extension and Adoption in China: A Case from Kaizuo Township, Guizhou Province'. The China Quarterly 206: 412-425. 
